\title{
El principio de objetividad en la Función Pública (un análisis desde la jurisprudencia)
}

\author{
Javier Guillén-Caramés \\ Profesor titular de Derecho Administrativo. \\ Universidad Rey Juan Carlos \\ Javier.guillen@urjc.es
}

\author{
Jesús Fuentetaja Pastor ${ }^{*}$ \\ Profesor titular de Derecho Administrativo \\ UNED \\ jfuentetaja@der.uned.es
}

\begin{abstract}
El principio de objetividad informa la Función Pública como institución pública, trascendiendo sus tradicionales consecuencias de neutralidad e imparcialidad exigidas a los funcionarios. Afecta decisivamente a todos los aspectos de su régimen jurídico, tanto en su regulación normativa como en las concretas decisiones de gestión de recursos humanos. En el presente artículo, se estudian algunas manifestaciones de la importancia del principio de objetividad desde la perspectiva del análisis jurisprudencial de algunos ámbitos decisivos, como son las clases de personal en la Función Pública, los procedimientos de ingreso y de provisión de puestos de trabajo, el ejercicio de la potestad de organización o la utilización de técnicas novedosas para la gestión de recursos humanos.
\end{abstract}

Palabras clave

Función Pública, Funcionarios, Selección.

\section{The principle of objectivity in the civil Service}

\begin{abstract}
The principle of objectivity informs the Civil Service as a public institution, transcending its traditional consequences of neutrality and impartiality required of civil servants. It decisively affects all aspects of their legal status, both in legislation and decisions on specific human resource management. In this paper, we study some practical implications of this relevant principle of objectivity from the perspective of case-law analysis of some critical areas, such as types of civil servants, procedures of recruiting or filling of jobs, the exercise of the power of organization and the use of novel techniques for the management of human resources.
\end{abstract}

Key words

Civil Service, civil servants, recruitment.

* Trabajo realizado al amparo del Proyecto de Investigación “El Estatuto Básico del Empleado Público y su desarrollo y aplicación en la Administración Local” (DER2010-17576), correspondiente a la convocatoria 2010 de ayudas para la realización de Proyectos de Investigación Fundamental no orientada del Ministerio de Economía y Competitividad. 


\section{PRINCIPO DE OBJETIVIDAD Y FUNCIÓN PÚBLICA}

El artículo 103 de la Constitución comienza afirmando, en el inicio de su apartado primero, que "la Administración Pública sirve con objetividad los intereses generales" y termina señalando, ya en su apartado tercero específicamente dirigido al estatuto de los funcionarios públicos, que éste regulará "las garantías para la imparcialidad en el ejercicio de sus funciones". La coherencia estructural interna del fundamento constitucional del estatuto jurídico de la Administración Pública muestra la importancia que presenta el principio de objetividad en la Función Pública.

De esta manera, la objetividad en la Función Pública se despliega tanto sobre su dimensión organizativa (lo que tradicionalmente se denomina «relación orgánica» y que se desborda en toda la vertiente estructural del aparato burocrático de las Administraciones Públicas) como sobre su vertiente subjetiva, es decir, sobre la relación de servicio que constituye el núcleo de derechos y obligaciones del estatuto funcionarial. La imbricación de ambas perspectivas determina la configuración institucional de una Función Pública que posibilite a los funcionarios servir con objetividad e imparcialidad los intereses generales.

Así lo refleja el Estatuto Básico del Empleado Público de 2007 cuando, entre los fundamentos de actuación que proclama en su artículo primero, incluye la "objetividad, profesionalidad e imparcialidad en el servicio garantizadas con la inamovilidad en la condición de funcionario de carrera".

Se ha sostenido que el principio constitucional de objetividad es predicable sólo de las Administraciones Públicas en cuanto tales y no de sus funcionarios. Disquisición bizantina y falaz, por cuanto aquellas operan a través de estos. No sólo informa la actuación de los funcionarios individualmente sino también a la Función Pública, institucionalmente, cuya configuración estructural debe responder a las exigencias que se derivan de dicho principio, con consecuencias fundamentales en ámbitos como las clases de personal admisibles en la Función Pública, las potestades de organización de la Administración, los procedimientos de ingreso en aquella o los de provisión de puestos en su seno.

De lo anteriormente expuesto se desprende también que la concepción constitucional y legal del principio de objetividad en la Función Pública se refiere, fundamentalmente, a la imparcialidad de los funcionarios públicos, término de referencia subjetivo que el EBEP, además, amplia a todos los empleados públicos. Esta imparcialidad de los funcionarios públicos, obviamente, trasciende la generalidad de las reglas del procedimientos administrativo (articulada a través de las reglas de abstención y recusación) para concretarse en la neutralidad absoluta del funcionario en el desempeño de sus obligaciones, de manera que el fundamento y finalidad de su actuación sean exclusivamente el interés general y la estricta legalidad de sus decisiones, sin acepción de personas, grupos, partidos políticos o

152 gobiernos. 
En este sentido, la objetividad de la Función Pública no es solo predicable de la actuación singular y operativa de sus funcionarios sino que, de una manera más decisiva y general, hace referencia a la configuración normativa e institucional de la Función Pública en cuanto tal, que debe regular y prever todas las técnicas necesarias para posibilitar el desempeño objetivo de los funcionarios y empleados públicos. A este respecto, se cita de manera un tanto simplificadora, pero expresiva, la "inamovilidad en la condición de funcionario", pero lo cierto es que esa objetividad institucional de la Función Pública se debe manifestar igualmente en todos y cado uno de los aspectos de la relación orgánica y de servicio: desde las clases de personal que se prevén en su seno, hasta las novedosas técnicas de gestión de recursos humanos, pasando por el decisivo momento de la selección de funcionarios, por las formas de provisión de puestos de trabajo o por el siempre difuso alcance de la potestad de organización en el ámbito de la Función Pública.

Para analizar el principio de objetividad en la Función Pública, abordaremos, pues, estos ámbitos a partir de las resoluciones jurisdiccionales que han debido precisar su alcance, advirtiendo que ni los ámbitos de estudio ni las sentencias que los ilustran pueden ser exhaustivos en un trabajo de estas características.

\section{PRINCIPIO DE OBJETIVIDAD Y CLASES DE PERSONAL}

\section{El personal eventual no garantiza la objetividad en la Función Pública}

La jurisprudencia ha procurado restringir los abusos de las Administraciones a la hora de crear puestos de personal eventual y de excederse en la atribución de funciones. Partiendo de la premisa legal ("funciones expresamente calificadas como de confianza o asesoramiento especial”) y constitucional (toda excepción al régimen funcionarial debe ser interpretada restrictivamente, amén de motivada), el Tribunal Supremo no ha dudado en interpretar sistemáticamente esta figura con la de los puestos que pueden desempeñar contratados laborales en las Administraciones Públicas (STS 12 de diciembre de 1997) para llegar a la conclusión de que las funciones que puede desempeñar el personal eventual no pueden ser identificadas con cometidos que encarnan tareas de carácter permanente dentro de la organización administrativa.

Pero el Tribunal Supremo, en su Sentencia de 7 de marzo de 2005, relativa a un puesto de Director Técnico de Urbanismo de un Ayuntamiento clasificado como eventual, no se detuvo en la ilegalidad de su consideración y llevó a cabo una serie de puntualizaciones de gran trascendencia para comprender adecuadamente esta figura. "La primera es que la Constitución viene a establecer un verdadero estatuto ineludible en todos los empleados públicos que prestan servicios profesionales para el Estado, cualquiera que sea la naturaleza de su vínculo, claramente deducible de lo establecido en sus artículos 103 (apartados 1 y 3) y 23.2. Las notas principales de este estatuto constitucional son el acceso de acuerdo con los principios de igualdad, mérito y capacidad, y la garantía para la imparcialidad en el ejercicio de sus funciones, que 
están directamente conectadas con los postulados de objetividad y eficacia proclamados para la actuación de la Administración pública. La segunda puntualización es que el contenido y significación de la expresión «confianza y asesoramiento especial», que legalmente se utiliza para definir y caracterizar al personal eventual, debe determinarse poniendo en relación aquella expresión con el régimen de nombramiento y cese legalmente previsto para el personal eventual. Ese nombramiento y cese es libre y corresponde a los superiores órganos políticos (Ministros, Secretarios de Estado, Consejeros de Gobierno de las Comunidades Autónomas y Presidentes de las Corporaciones Locales) y, por lo que en concreto hace al cese, está establecido que se producirá automáticamente cuando cese la autoridad a la que se preste la función de confianza o asesoramiento (artículos 20.2 LMRFP y 104.2 de la LBRL). Todo lo cual pone de manifiesto que se trata de tareas de colaboración inmediata con quienes ostentan el poder de superior decisión política, en las que predominan las notas de afinidad y proximidad política que es inherente a la «confianza». Pues bien, la ponderación conjunta de esas dos puntualizaciones impone concluir que los puestos reservados a personal eventual son excepcionales y su validez está condicionada a que sus cometidos se circunscriban a esas funciones de «confianza y asesoramiento especial» que legalmente delimitan esta específica clase de personal público. Y la consecuencia paralela que también se extrae es que deben quedar vedadas a ese personal eventual las actuaciones de colaboración profesional que se proyecten en las funciones normales de la Administración pública, bien en las externas de prestación y policía frente a la ciudadanía, bien en las internas de pura organización administrativa. Estas actuaciones profesionales, por la directa conexión que tienen con los principios constitucionales de objetividad y eficacia administrativa, deben ser asignadas al personal público seleccionado bajo los principios de igualdad, mérito y capacidad. Las funciones del puesto litigioso que la sentencia recurrida describe rebasan el límite legal de «asesoramiento y confianza especial», ya que expresan cometidos profesionales de colaboración en típicas actividades administrativas".

\section{Personal directivo ¿funcionario o laboral?}

La fallida conceptualización del personal directivo como una clase de personal específica ha implicado la imposibilidad de superar la alternativa dicotómica funcionarios-laborales a la hora de repartir los puestos de trabajo que tengan asignadas funciones directivas. Se reproduce, por tanto, para estas funciones el citado reparto de puestos entre funcionarios y laborales. Así pues, la regla general será que los puestos de trabajo en las Administraciones Públicas que tengan asignadas funciones directivas deberán ser ocupados por funcionarios, en tanto en cuanto su estatuto jurídico de inamovilidad y estabilidad garantiza mejor el desempeño objetivo e imparcial de estas funciones.

Así lo destacó la Sentencia del Tribunal Supremo de 13 de mayo de 2009, que anuló un Acuerdo del Consejo de Gobierno del Principado de Asturias por el que se 154 creaban, en la Administración de dicha Comunidad y dentro del catálogo de personal 
laboral, tres puestos de trabajo: Jefe Área de Servicios Sociales Comunitarios y Prestaciones, Jefe Área Planificación y Programación y Jefe Área Recursos y Servicios. Para el Tribunal, tal Acuerdo vulnera artículo 15.1.c) de la Ley 30/1984, que establece los puestos que pueden ser ocupados por personal laboral en la Administración Pública. En efecto, la literalidad de ese precepto legal claramente señala que, por lo que hace a los puestos de trabajo de la Administración, la regla general es el estatuto funcionarial y lo excepcional el régimen laboral; y esto hace que hayan de interpretarse restrictivamente las excepciones que en dicho precepto se enumeran. Lo segundo que debe subrayarse es que, en caso de duda, habrá de efectuarse una interpretación que tenga en cuenta cuáles son las notas fundamentales que se toman en consideración en el conjunto de esos casos que directamente son enumerados en el tan repetido precepto como hábiles para encarnar la excepción. Y estas notas son algunas de las siguientes: la temporalidad del puesto; su contenido coincidente con actividades propias de oficios o profesiones existentes en el sector privado, lo que equivale a señalar que se trata de puestos que no difieren en nada con los que puedan existir en dicho sector; su carácter instrumental en todo lo relativo a edificios y demás medios materiales de la Administración; o su carácter siempre secundario, auxiliar o de mera colaboración cuando tengan asignadas funciones administrativas. Y lo tercero a tener en cuenta es que, tratándose de funciones directivas o de organización dentro de la Administración, el estatuto funcionarial, por la mayor inamovilidad y estabilidad que comporta para el empleado público, es el que mejor garantiza el principio de objetividad (artículo 103 de la Constitución) que debe presidir cualquier función de dirección administrativa. Los puestos aquí litigiosos son Jefaturas de determinadas áreas administrativas, lo cual significa estas dos cosas: que no es de apreciar en ellos ninguna de esas notas que antes se señalaron como caracterizadoras de las excepciones en que legalmente se permite el régimen laboral; $y$, además, encarnan unos cometidos de dirección administrativa en los que resulta muy conveniente la mayor garantía de objetividad que significa el estatuto funcionarial".

\section{LA OBJETIVIDAD EN EL ACCESO A LA FUNCION PÚBLICA: ALGUNAS MANIFESTACIONES JURISPRUDENCIALES}

\section{Aspectos generales de la jurisprudencia del TC sobre el acceso y la objetividad (art. 23.2 CE)}

El art. 23.2 Ce establece de forma expresa que los ciudadanos "tienen derecho de acceder en condiciones de igualdad a las funciones y cargos públicos, con los requisitos que señalen las leyes". Este apartado del citado precepto es una concreción del principio de igualdad y no se refiere de manera exclusiva a los cargos representativos. De este modo, el art. 23.2 CE ha de conectarse con el art. 103.3 CE que señala que la "ley regulará el estatuto de los funcionarios públicos, el acceso a la función pública de acuerdo con los principios de mérito y capacidad".

1 A propósito de la STC 27/2012, de 1 de marzo. 
Un primer dato que ha sido resaltado respecto a las principales líneas que delimitan la doctrina constitucional sobre el alcance del art. 23.2, es que se trata de un derecho de configuración legal, correspondiendo al legislador la delimitación de su contenido, así como el establecimiento de los criterios que permitan el acceso a las funciones públicas en condiciones de igualdad (STC 10/1989, de 24 de enero).

Igualmente, el art. 23.2 CE configura un derecho reaccional que no atribuye el derecho a desempeñar determinadas funciones públicas, sino que lo que establece en la posibilidad de reclamar ante los Juzgados y Tribunales de Justicia toda norma o aplicación de la misma que vulnere la igualdad establecida en dicho preceptos (STC 185/1994, de 20 de junio).

A su vez el TC ha puesto especial énfasis en destacar el principio de igualdad como núcleo esencial del derecho de acceso a las funciones públicas. Por tanto, para salvaguardar este principio la jurisprudencia constitucional ha establecido las siguientes garantías constitucionales que han sido sistematizadas en la STC 27/2012, de 1 de marzo:

- En primer lugar, se trata de un derecho a la predeterminación normativa del procedimiento de acceso a las funciones públicas, de acuerdo con los requisitos que establezcan las leyes. De este modo, dicha predeterminación normativa "entraña una garantía de orden material que se traduce en la fijación ex ante de los criterios de selección, tanto de carácter absoluto como relativo, en que consistan la igualdad, mérito y capacidad para cada función, siendo ésta la única forma de que pueda ejercerse el derecho mismo". De esta manera, los participantes en este tipo de procesos pueden conocer de antemano cuales con las condiciones y requisitos que rigen el proceso y, de otro lado, la administración queda sujeta, en la valoración de los candidatos, al contenido predeterminado por la norma.

- En segundo lugar, e íntimamente conectado con el apartado anterior, se trata de un derecho de acceso a las funciones públicas en condiciones de igualdad, lo que implica que las normas que regulan los procesos selectivos han de garantizar a los ciudadanos "una situación jurídica de igualdad en el acceso a las funciones públicas, con la inmediata interdicción de requisitos de acceso que tengan carácter discriminatorio, o de referencias individualizadas" (SSTC 193/1987, de 9 de diciembre; 47/1990, de 20 de marzo; 353/1993, de 29 de noviembre y 67/1989, de 18 de abril). De este modo, el TC ha advertido que las normas que regulen esos procesos "deben, para respetar el principio de igualdad, establecer los requisitos y condiciones de acceso en términos abstractos y generales, con la interdicción de cualquier referencia individualizada o de convocatorias ad personam y de requisitos discriminatorios" (SSTC 60/1986, de 20 de mayo; 148/1986, de 25 de noviembre y 27/1991 de 14 de febrero). Igualmente, encuadrado dentro de este principio, se ha exigido que las condiciones y requisitos que se establezcan sean referibles a los principios de 
mérito y de capacidad, estableciéndose la obligación de "no exigir para el acceso a la función pública requisito o condición alguna que no sea referible a los indicados conceptos de mérito y capacidad, de manera que pueden considerarse violatorios del principio de igualdad todos aquellos que sin esa referencia, establezcan una diferencia entre ciudadanos"(STC 138/2000 de 29 de mayo).

- Finalmente, el derecho establecido en el art. 23.2 CE incorpora, asimismo, el derecho a la igualdad en la aplicación misma de la Ley, de tal modo que, una vez se garantice la vinculación de la propia Administración a lo señalado en las normas que regulan el procedimiento selectivo, ha de quedar igualmente excluida toda diferencia de trato en el desarrollo del citado procedimiento.

Por lo tanto, puede afirmarse que el art. 23.2 CE garantiza que las normas que regulen los procesos selectivos no puedan establecer diferencias entre los participantes que carezcan de una justificación objetiva y razonable y que no sean desproporcionadas, que los requisitos de acceso y criterios de selección se dispongan en términos generales y abstractos, y, además, que se encuentren referidos a los principios de mérito y capacidad.

Sin embargo, como destaca la jurisprudencia constitucional, resulta necesario hacer un apunte esencial en relación con el alcance del principio de igualdad que garantiza el art. 23.2 CE. Así, en determinados supuestos extraordinarios se ha considerado acorde con la $\mathrm{CE}$, que en algunos procesos selectivos de acceso a funciones públicas se establezca un trato de favor en relación a unos participantes respecto de otros. Esta excepción a la regla general es legítima en supuestos verdaderamente singulares, en los que las especiales circunstancias de una Administración y el momento concreto en el que se celebren este tipo de pruebas, pueda verse justificada la desigualdad de trato de los participantes, beneficiando a aquellos que ya habían prestado en el pasado servicios profesionales en situación de interinidad en la Administración convocante, como ocurre en el caso resuelto por la STC 27/2012, de 1 de marzo.

Esta serie de supuestos puede variar desde la celebración de pruebas restringidas, a pruebas en las que se primara de forma muy notable los servicios desarrollados en la administración, si bien tanto en uno como en otro caso, ha existido siempre una justificación de las singulares y excepcionales circunstancias de que manera expresa se establecían en cada una de las convocatorias.

Por lo tanto, puede afirmarse que para que sea constitucionalmente legítimo establecer un proceso selectivo restringido o uno en el que se prime de manera notable un mérito concreto en relación a otros, debe darse una justificación amparada en una situación excepcional, ya que de no ser así, se estaría vulnerando el contenido del art. 23.2 CE.

De este modo, en la cuestión de inconstitucionalidad planteada por la sección primera de la Sala de lo Contencioso-administrativo del TSJ de Andalucía, en relación 
con la disposición transitoria cuarta de la Ley del Parlamento de Andalucía 8/1997, de 23 de diciembre, por la que se aprobaban medidas en materia tributaria, presupuestaria, de empresas de la Junta y otra entidades, de recaudación, de contratación, de función pública y de fianzas de arrendamientos y suministros, en relación con el baremo que figura como anexo a la misma, en lo relativo a la puntuación de la fase de concurso, por posible contradicción con los arts. 14 CE y 23.2 CE, y que ha sido resuelta por la ya citada STC 27/2102, el Alto tribunal tuvo que examinar si las valoraciones que esas contenían en la norma impugnada sobre la experiencia profesional de los candidatos respetaba o no el principio de igualdad que garantiza el art. 23.2 CE o si, por el contrario, se daba una desproporción en beneficio de unos candidatos y perjuicio de otros que conllevaba la vulneración del precepto constitucional. En el presente caso, el TC estimó que la valoración de la experiencia profesional en la citada norma andaluza, implicaba un beneficio desproporcionado y no objetivo a unos participantes en el proceso selectivo respecto de otros.

\section{Manifestaciones de la jurisprudencia Tribunal Supremo sobre el acceso a la función pública y el principio de objetividad}

\subsection{Sobre el acceso y la imposición de un límite de edad en una convocatoria de oposiciones ${ }^{2}$}

En el presente asunto se aborda el problema de la igualdad en el acceso a la función pública en relación con el debate de si puede ser ajustada a Derecho una convocatoria de oposición libre para cubrir plazas, de aspirantes a ingreso en el Cuerpo Nacional de Policía, concretamente a su Escala Ejecutiva, que establecía un límite de edad de 30 años, y si dicha limitación puede encontrarse justificada de forma objetiva y razonable en función de determinadas circunstancias.

En primer lugar, se recuerda la jurisprudencia que el TC ha vertido sobre esta problemática relacionada con la imposición de límites de edad, concretamente en su STC 75/1983, de 17 de agosto, en la que se señaló que

"El artículo 14 CE configura el principio de igualdad ante la Ley como un derecho subjetivo de los ciudadanos, evitando los privilegios y las desigualdades discriminatorias entre aquéllos, siempre que se encuentren dentro de las propias situaciones de hecho, a las que debe corresponder un tratamiento jurídico igual, pues en tales supuestos la norma debe ser idéntica para todos, comprendiéndolos en sus disposiciones y previsiones con la misma concesión de derechos que eviten las desigualdades, pues de no actuarse legislativamente de tal manera, surgiría un tratamiento diferenciado a causa de una conducta arbitraria, o al menos no debidamente justificada, del poder público legislativo. Sólo le resulta posible al legislador, en adecuada opción legislativa, establecer para los ciudadanos un trato diferenciado, cuando tenga que re-

2 A propósito de la STS de 16 de mayo de 2012 (Rec. 3158/2011) 
solver situaciones diferenciadas fácticamente con mayor o suficiente intensidad, que requieran en su solución por su mismo contenido una decisión distinta, pero a tal fin resulta indispensable que exista una justificación objetiva y razonable, de acuerdo con criterios y juicios de valor generalmente aceptados, cuya exigencia deba aplicarse en relación con la finalidad y efectos de la medida considerada, debiendo estar presente por ello una razonable relación de proporcionalidad entre los medios empleados y la finalidad perseguida, y dejando en definitiva al legislador con carácter general la apreciación de situaciones distintas que sea procedente diferenciar y tratar desigualmente, siempre que su acuerdo no vaya contra los derechos y libertades protegidos en los artículos 53.1 y 9.3 CE, ni sea irrazonada, según deriva todo ello de la doctrina establecida por este Tribunal Constitucional (...). Para analizar correctamente la constitucionalidad del precepto cuestionado es menester precisar que la prohibición de discriminación, enunciada con carácter general en el artículo $14 C E$, y concretamente en cuanto al acceso y a la permanencia en los cargos y en las funciones públicas, en el artículo 23.2 $C E$, responde a uno de los valores superiores que según la Constitución han de inspirar el ordenamiento jurídico Español, el valor de la igualdad (artículo 1.1). El derecho a la igualdad tiene así un carácter general que comprende a los servidores públicos y actúa, en el acceso a la función pública, y a lo largo de la duración de la relación funcionarial, de modo que los ciudadanos no deben ser discriminados para el empleo público o una vez incorporados a la función pública. La edad no es de las circunstancias enunciadas normativamente en el artículo 14, pero no ha de verse aquí una intención tipificadora cerrada que excluya cualquiera otra de las precisadas en el texto legal, pues en la fórmula del indicado precepto se alude a cualquier otra condición o circunstancia personal o social, carácter de circunstancia personal que debe predicarse de la edad; de modo que la edad dentro de los límites que la Ley establece para el acceso y la permanencia en la función pública es una de las circunstancias comprendidas en el artículo 14 y en el artículo 23.2, desde la perspectiva excluyente de tratos discriminatorios. Pero sería equivocado inferir de aquí que todo funcionario, desde el momento del acceso a la función pública y en tanto no se haya operado la extinción conectada a la edad de jubilación, tiene abiertas, cualquiera que sea su edad, las posibilidades de ocupar cualquier puesto de la organización pública, pues, por el contrario, en cuanto la edad es en sí un elemento diferenciador será legítima una decisión legislativa que, atendiendo a ese elemento diferenciador, y a las características del puesto de que se trate, fije objetivamente límites de edad que suponga, para los que la hayan rebasado, la imposibilidad de acceder a estos puestos".

\section{El máximo intérprete de la Constitución concluyó que}

"Ia diferenciación no constituye un específico privilegio -o su contrario, una discriminación- por razón de la edad, sino una definición objetiva y general de las condiciones que han de reunir los Interventores que quieran acceder a los Municipios de régimen especial. La igualdad de tratamiento entre los funcionarios que integran el cuerpo nacional que puedan concursar a la plaza de Barcelona (al igual que a la de Madrid) se produce en términos abstractos, pues todos ellos, antes de cumplir la edad de 60 años, pueden hacerlo sin excepción si concurren todas las demás condiciones legales, por lo que poseen en este sentido y alcance igualdad de oportunidades para el posible acceso a la plaza, aunque su adjudicación se decida por el mayor mérito debido a la apreciación de otros parámetros estimativos, surgiendo después de rebasar esa edad de 60 años para todos la misma prohibición de concursar". 
En parecidos términos se había ya expresado el TS en su sentencia de 22 de febrero de 1986 en la que afirmaba que el principio de igualdad plasmado en el art. 14 CE

"no puede interpretarse en el sentido, tan incondicional como absurdo, de que toda persona, por el hecho de serlo, esté en condiciones de acceder al desempeño de cualquier cargo, profesión, función u oficio, porque para esto es indispensable estar en posesión de una titulación específica, de unos conocimientos que no son patrimonio de todos, de una determinada edad, del cumplimiento de determinadas pruebas, etc., siendo, por ende, aplicable, en casos como el presente, el 103.3 de la propia Constitución regulador del acceso a la función pública "de acuerdo con los principios de mérito y de capacidad", no aquel otro de igualdad invocado, aunque, evidentemente, ésta deba tenerse en cuenta, presupuestos esos peculiares requisitos o condiciones, por parte de quienes aspiren al desempeño de la función, con la consecuencia de que no pueda estimarse que existe discriminación cuando, en consideración a aqueIlas cualidades, se está en presencia de situaciones fácticas diferentes (...), por lo que no se puede apreciar discriminación alguna cuando la diferencia de trato viene impuesta por una necesaria capacitación y la inevitable exigencia de condiciones o requisitos de carácter profesional, con tal de que, en una clara relación de proporcionalidad entre los medios empleados y la finalidad perseguida, sea adecuada a la naturaleza propia de las tareas a realizar y se establezcan con carácter general, teleología aquella que no era otra en este caso que la de poder así designar para el cargo al aspirante más capacitado".

De este modo queda claro que puede haber justificaciones objetivas y razonables para el establecimiento de un límite de edad para el ingreso por el turno libre y, en consecuencia, no se da una vulneración del principio de igualdad, puesto que la fijación de un límite de edad se trata de una valoración reservada a la Administración. De hecho, la edad puede ser utilizada como un límite para acceder a la función pública no sólo mediante la fijación de la mínima que se ha de tener para poder participar en procesos selectivos, sino también a través de la imposición de una máxima. Así, lo establece el vigente art. 56.1.c) del EBEP que dice:

“1. Para poder participar en los procesos selectivos será necesario reunir los siguientes requisitos:

c) Tener cumplidos dieciséis años y no exceder, en su caso, de la edad máxima de jubilación forzosa. Sólo por Ley podrá establecerse otra edad máxima, distinta de la edad de jubilación forzosa, para el acceso al empleo público".

Por lo tanto, puede afirmarse que lo establecido en dicho precepto por lo que respecta a la edad máxima es que sea otras que I establecida para la jubilación forzosa. Igualmente, resulta posible establecer otras inferiores por Ley, en cuanto excepciones, que deberán estar justificadas de forma objetiva desde el prisma de constitucionalidad de la igualdad.

En el presente caso se discutía acerca de si el establecimiento de una edad de 30 años para el acceso por el turno libre a la Escala Ejecutiva del Cuerpo Nacional de 160 Policía era o no conforme al canon de constitucionalidad que hemos destacado, en 
función de si se dan o no razones que de forma objetiva justifiquen la desigualdad. En este análisis el TS concluye señalando que

\begin{abstract}
"Son términos de comparación que estimamos válidos porque no concurren entre las situaciones a las que hacen referencia diferencias sustanciales con la que ocupa el Sr. García Espinar. Así, si un miembro de la Escala Básica puede acceder a la Escala Ejecutiva con más de treinta años no se ve por qué motivo se le ha de prohibir hacerlo a quien aspira a ingresar por el turno libre. El ingreso previo en la otra Escala y los requisitos que dentro de ella se hayan de cumplir para estar en condiciones de participar en las pruebas selectivas por el turno libre no quitan la conclusión de que a los treinta y cinco años es posible desempeñar sin dificultad las funciones de la Escala Ejecutiva y, si por promoción interna ese acceso se puede producir más tarde, el argumento que utilizamos se fortalece. Dicho de otro modo, las circunstancias específicas que afectan a los integrantes de la Escala Básica a la hora de situarse en condiciones de opositar por libre o de servirse de la promoción interna no guardan relación con la configuración objetiva de los cometidos de la Escala Ejecutiva. Y lo mismo ha de decirse respecto de los Mozos de Escuadra ya que no se aprecian diferencias significativas entre los cometidos de los Inspectores del Cuerpo Nacional de Policía y las de los Inspectores de ese cuerpo autonómico. Teniendo en cuenta que los Mozos de Escuadra ejercen en Cataluña las mismas funciones que la Policía Nacional en otros lugares de España, ha de concluirse que a los cuarenta años no hay obstáculos para desempeñar las propias de la Escala Ejecutiva de esta última".
\end{abstract}

En definitiva, el principio de objetividad entra en juego a la hora de justificar la imposición de determinados requisitos de edad en determinadas pruebas de acceso a la función pública con el fin de servir de juicio de justificación del principio de igualdad de acceso establecido en el art. 23.2 CE.

\title{
2.2. Procedimiento selectivo y virtualidad del principio de objetividad ${ }^{3}$
}

En el siguiente caso se trata el problema del enjuiciamiento del sistema de valoración de méritos en un proceso selectivo, concretamente, se examinan si los criterios de baremación eran o no objetivos.

Los hechos se concretan en la exclusión de un alumno del curso de policía del País Vasco del proceso selectivo convocado por la Directora de la academia del Policía de la citada Comunidad Autónoma para ingreso en la categoría de agente de la escala básica de la Ertzaintza, en la que se le consideró no apto al no superar el curso de formación.

El proceso selectivo, según la convocatoria, constaba de una fase de concursooposición, un curso de formación y un período de prácticas, todos eliminatorios. La oposición consistía en varias pruebas. La primera comprendía: 1. un test sobre los contenidos de los programas oficiales (50 puntos); 2. ejercicios dirigidos a evaluar el

3 A propósito de la STS de 27 de febrero de 2012 (Rec 1978/2009). 
nivel de inteligencia, la capacidad de abstracción y concreción, la capacidad verbalnemotécnica y el razonamiento numérico (150 puntos); 3. un test de personalidad encaminado a evaluar sus rasgos y los posibles factores psicopatológicos ( 50 puntos siendo necesarios 25 para aprobar). La segunda prueba de la oposición eran los cinco ejercicios físicos (100 puntos a razón de 20 puntos cada uno, siendo necesarios 50 para aprobar). Y la tercera prueba comprendía un test de personalidad orientado al estudio de la adecuación al perfil requerido (75 puntos) y una entrevista personal o grupal en la que se valorarían las habilidades sociales, el manejo de situaciones, la capacidad de expresión en grupo y la de razonamiento (75 puntos).

En el concurso se valoraría con hasta 50 puntos el conocimiento del euskera. El resultado final del concurso-oposición vendría determinado por la suma de las puntuaciones, dirimiendo los empates el nivel de euskera y, en su caso, la calificación de la tercera prueba de la oposición. Quienes lo superasen, previa comprobación de que no estaban afectados por ninguna causa médica de exclusión, serían nombrados funcionarios en prácticas.

El curso de formación a realizar en la Academia de Policía del País Vasco en régimen de internado, tenía carácter selectivo, se desarrollaría según el Plan de Estudios de la Academia y era necesario aprobarlo para pasar a la fase de prácticas, a cuyo término los aspirantes que hubiesen superado todo el proceso selectivo serían nombrados agentes de la Escala Básica de la Ertzaintza. Entre el curso y las prácticas no podrían sobrepasar treinta meses de duración.

El Plan de Estudios contemplaba un sistema de evaluación en el que, sobre un total de 1.000 puntos, 600 se adjudicaban por exámenes o pruebas de tipo test, 300 puntos por la Valoración de Actitudes y 100 por la ficha disciplinaria. A su vez, esa Valoración de Actitudes comprendía cuatro partes [Habilidades Sociales y Adaptabilidad (105 puntos), Actitud en Clase (70 puntos), Capacidad de Trabajo en Grupo (60 puntos) y Relaciones Interpersonales en Grupo -Sociograma- (65 puntos)]. Para superar esta Valoración de Actitudes era necesario obtener un mínimo de 150 puntos.

La razón por la que no se le tuvo por apto al recurrente reside en que solamente logró 133,929 puntos en Valoración de Actitudes. Fue determinante de tal resultado que en el Sociograma quedase en 8 puntos sobre los 65 que se podían adjudicar en él. La puntuación de esta prueba se establece en función de la opinión que sobre el interesado manifiestan sus compañeros de grupo, una treintena, a partir de la descripción de tres distintas situaciones propias de la actividad policial en las que los alumnos han de indicar a quienes querrían como compañeros y quienes no querrían para afrontarlas. Sociograma cuyos resultados se ampliaban y validaban en la entrevista de profundización y contraste que debían realizar después los tutores.

La cuestión, por tanto, giraba en torno a si dicha Valoración de Actitudes era conforme a los principios de objetividad y de discreción, de cara a garantizar los prin162 cipios de mérito y capacidad previstos en la CE para el acceso a la función pública. 
EI TS en el presente asunto señaló la vulneración del principio de objetividad necesario en la prueba del Sociograma, señalando que

“(... ) la existencia de grupos que bajo la incitación de quienes se erigen en sus impulsores crean un clima de animadversión o desprecio contra algunos compañeros sin que haya razón que lo justifique invalidan tales pruebas desde el punto de vista de la objetividad como medio de medir o evaluar las actitudes relevantes para la función policial pues las respuestas dadas por la mayoría obedecen, no a percepciones espontáneas relacionadas con cometidos profesionales, sino a la imagen distorsionada difundida de la manera indicada.

En este contexto, fue posible que se impusiera entre los alumnos una impresión negativa del recurrente por atribuírsele por quienes tenían una indebida capacidad de influencia, a partir de hechos falsos, actitudes insolidarias que en ningún momento existieron, impresión que condicionó el resultado del Sociograma (...)

(...) si a todo lo anterior añadimos que los profesores que entrevistaron al recurrente carecen de preparación profesional en psicología y que no rellenaron ficha alguna al respecto -no consta en el expediente y en la demanda sí se hizo referencia a este extremo-podemos concluir que la prueba del Sociograma se llevó a cabo sin que se dieran las condiciones mínimas necesarias para asegurar la objetividad que, según el artículo 21 del Reglamento de Régimen Interior de la Academia de Policía del País Vasco, han de tener los mecanismos de evaluación de actitudes ni el respeto a los principios del mérito y la capacidad y, por tanto, se produjo la infracción de los artículos 23.2 (LA LEY 2500/1978) y 103.3 de la Constitución, así como del artículo 9.3 pues en la exclusión del Sr. (...) fue determinante el resultado de dicho Sociograma".

\subsection{Vulneración del principio de imparcialidad 4}

En este asunto los hechos se iniciaron en virtud del recurso contencioso-administrativo que interpuso doña Encarna contra la desestimación por el Gobierno de Navarra, por resolución de su Departamento de Presidencia, Justicia e Interior de 7 de mayo de 2001 del recurso de alzada que pretendía la nulidad de la primera prueba de la oposición convocada para proveer nueve plazas de encargado de biblioteca por resolución de 3 de abril de 2000 del Director General de la Función Pública. La recurrente fue eliminada en esa primera prueba consistente en la contestación a unos cuestionarios seleccionando la correcta de las respuestas alternativas presentadas al aspirante y, entre otros motivos, en su demanda alegó que en el acto de realización del ejercicio se les indicó a los participantes por los miembros del tribunal calificador que hicieran constar en las hojas de respuestas sus nombres y apellidos y que podían utilizar tipex para corregir las respuestas que quisieran modificar. Asimismo, hizo constar que no se les permitió llevarse una copia de sus ejercicios y que no se hicieron públicas las contestaciones válidas. Las bases de la convocatoria, que no fueron im-

4 Apropósito de la STS de 19 de enero de 2009 (Rec 8098/2004). 
pugnadas, no disponían expresamente que el primer ejercicio se hiciera sin identificación de los participantes en las pruebas.

De entre los motivos por los que se consideraba contraria al ordenamiento jurídico la actuación seguida por el tribunal calificador y, por tanto, la del Gobierno de Navarra que la había confirmado, se encontraban los relativos a la quiebra del principio de imparcialidad que debe presidir el proceder de la Administración en los procesos selectivos para hacer efectiva la igualdad en el acceso a la función pública cuyo respeto impone el artículo 23.2 CE. Dice la sentencia recurrida que el anonimato de los ejercicios escritos que no vayan a ser leídos ante el tribunal es un requisito que no es necesario que venga exigido expresamente en las bases, pues, como cualquier otro que sea condictio sine qua non de igualdad o imparcialidad, es consustancial a esos principios. Así, pues, la realización del primer ejercicio debió tener lugar sin que constara en las hojas de respuesta la identidad del opositor. Se trata de una medida posible y necesaria que el tribunal calificador debió adoptar para excluir toda posible ventaja a favor de alguno o algunos de los participantes en vez de utilizar un procedimiento que permitía el trato desigual.

Por lo tanto, la discusión gira en torno a si la Comunidad Foral Navarra vulneró los principios de igualdad y legalidad a que alude el art. 9.3 CE, así como el principio de objetividad de la Administración que viene impuesto por el art. 103.1 CE y 106.1 CE que somete la actuación administrativa a los fines que la justifican., en el proceso selectivo de acceso a la función pública.

Al respecto, el TS señala que la garantía de la igualdad en el acceso a la función pública, así como de la imparcialidad y objetividad que debe guardar toda actuación de la Administración en los procesos selectivos se asegura impidiendo que los ejercicios contengan la identidad de los aspirantes. Por tanto, afirma que

"la aplicación correcta de las bases exigía que el primer ejercicio de la oposición se hiciera asegurando que, a la hora de corregirlo, no constara en las hojas de respuestas a los cuestionarios la identidad del aspirante al que correspondía. Esta exigencia no es ajena a aquellos artículos del texto fundamental y, si bien se mira, tampoco a las bases de la convocatoria pues, aunque nada dicen de cómo debía llevarse a cabo materialmente la prueba, sí marcan la diferencia entre la primera y la segunda desde el momento en que exigen que el ejercicio en que consistía esta última fuera leido ante el tribunal calificador. Eso supone que aquí excluye por razones obvias el anonimato. Ahora bien, el silencio respecto a cómo tenía que hacerse la primera no autorizaba a que se realizase sin asegurarlo".

\subsection{El requisito de la publicidad como garantía del principio de objetividad ${ }^{5}$}

Un aspecto relevante en los procesos selectivos es el de la necesaria publicidad de las decisiones que adoptan los tribunales calificadores de dichos procesos. El prin- 
cipio de publicidad, en su manifestación más genérica, se encuentra ligado a otros mandatos constitucionales como los son el derecho fundamental a la tutela judicial efectiva del art. 24 CE y el principio de objetividad que para toda actuación de las Administraciones Públicas predica el art. 103.1 del texto constitucional.

En el asunto que pasamos a comentar los hechos se circunscriben en torno la falta de publicidad en la forma de cálculo de determinados baremos que eran esenciales para obtener la calificación de apto o no apto por parte del tribunal calificador del proceso selectivo y que llevaron a la no superación del segundo ejercicio por parte de los recurrentes.

Al respecto, el TS establece que la omisión del principio de publicidad conlleva

"tanto la necesidad de que toda actuación administrativa sea transparente en los hechos, criterios y razones que determinen sus decisiones, pues solo así es posible el control que demanda el derecho de tutela judicial efectiva; como también que esos criterios estén establecidos con anterioridad a su finalización cuando de procedimientos competitivos se trate, porque de esta manera es como queda conjurado con las debidas garantías el riesgo del favoritismo individual (contrario al principio de objetividad) que se produciría si los criterios de valoración de los aspirantes fuesen definidos una vez realizadas esas pruebas competitivas.

También debe recordarse que esa publicidad aplicable a los procedimientos administrativos de selección, dispuesta por el mencionado Reglamento, no hace sino ratificar el mismo mandato que se establecía en el artículo 19.1 de la Ley 30/1984, de 2 de agosto, de Medidas para la Reforma de la Función Pública y actualmente aparece, con el de transparencia, en el artículo 55.2 Ley 7/2007, de 12 de abril, del Estatuto Básico del Empleado Público.

Asimismo debe significarse que esa transparencia de que se viene hablando es también un principio de actuación de la Administración pública proclamado con carácter general en el artículo 3.5 de Ley 30/1992, de 26 de noviembre, de Régimen Jurídico de las Administraciones Públicas y del Procedimiento Común".

De este modo, el TS estima la pretensión de los recurrentes y fija el alcance de dicha estimación teniendo en cuenta las siguientes consideraciones:

"Que en lo posible debe respetarse el derecho de los aspirantes ya aprobados actuantes de buena fe, que no tienen por qué sufrir las consecuencias de unas irregularidades que no les son imputables.

Que lo anterior no hace ya factible retrotraer las actuaciones al momento anterior a la celebración del segundo ejercicio para que, como habría sido lo más lógico, primero el Tribunal Calificador fijara la nota de corte determinante del "no apto" y los elementos o factores ponderables en esa evaluación de la aptitud que corresponde a dicho ejercicio; $y$, después, se llevara a cabo su realización y corrección según esos criterios preestablecidos. 
$Y$ que tampoco la Administración demandada, tras conocer el planteamiento realizado en la demanda formalizada en la instancia, ha realizado alegaciones o practicado prueba que demuestre de manera inequívoca que el resultado del segundo ejercicio de los recurrentes merecía, desde cualquier parámetro técnico, un necesario juicio de falta de aptitud.

Consiguientemente, la estimación tiene que ser para que se declare aptos a los recurrentes en el segundo ejercicio y se les convoque a la prueba médica; y para que si el resultado de esta última arroja para ellos la calificación de aptos, se les otorgue la calificación final de la oposición que les corresponda según la suma de las puntuaciones del primer ejercicio en los términos que establecen las bases de la convocatoria y, en su caso, si por su puntuación les corresponde, sean incluidos en la relación definitiva de aspirantes que han aprobado la oposición en el lugar que les corresponda".

\section{POTESTAD DE ORGANIZACIÓN Y PRINCIPIO DE OBJETIVIDAD}

Para ilustrar en qué medida el principio de objetividad debe informar el ejercicio de la potestad de organización de las Administraciones Públicas en el ámbito de la Función Pública nos vamos a detener en la cuestión relativa a la determinación del complemento específico de los puestos de trabajo.

El complemento específico (o concepto análogo) es una retribución complementaria que tiene por objeto remunerar "la especial dificultad técnica, responsabilidad, dedicación, incompatibilidad exigible para el desempeño de determinados puestos de trabajo o las condiciones en que se desarrolla el trabajo": art. 24 b) EBEP). Por sus características, su cuantía es singular para cada puesto de trabajo en el que concurren los factores citados u otros que la Ley de Función Pública correspondiente haya previsto. La Administración, por tanto, goza de una gran discrecionalidad a la hora de fijar los montantes concretos en los correspondientes instrumentos de ordenación de los puestos de trabajo, lo que ha dado lugar a una gran conflictividad por las arbitrariedades que se han producido. En efecto, la cuantía de este concepto retributivo es uno de los más importantes de las remuneraciones totales del funcionario, de ahí que las unidades administrativas no hayan dudado en utilizarlo como medio para atraer funcionarios de gran cualificación (la búsqueda de puestos con altos niveles de complemento específico es la causa principal de que nuestra Función Pública padezca un trasiego continuo de funcionarios), pero también para recompensar a los que ya tenía, modificando las relaciones de puestos de trabajo en ese apartado, con lo que se bordeaba continuamente la objetividad de las decisiones de la Administración. Amén de las discriminaciones continuas entre funcionarios de igual nivel que ven cómo puestos, con funciones y características semejantes, son dotados de complementos específicos diferentes.

Según la STS de 1 de julio de 1994, dos son las características fundamentales del complemento específico: A) La concreción: se fija atendiendo precisamente a las ca166 racterísticas de «un» puesto de trabajo. B) La objetividad: se atiende a las condiciones 
particulares de ese puesto de trabajo y no a los Cuerpos o Escalas de los funcionarios que las desempeñan. Así las cosas, resulta claro que dentro de un mismo Centro o Dependencia administrativa funcionarios del mismo Grupo pueden desempeñar puestos de trabajo a los que corresponda distinto complemento específico: es el contenido del puesto de trabajo el que determina el complemento específico. Ya en este punto ha de destacarse que los datos a tener en cuenta para la fijación del complemento específico -especial dificultad técnica, dedicación, responsabilidad, incompatibilidad, peligrosidad o penosidad- integran conceptos jurídicos indeterminados que, en cuanto tales, tienen naturaleza reglada: o hay penosidad o no la hay, o no hay peligrosidad o no, etc. No aparece pues en la determinación del complemento específico la discrecionalidad administrativa -no resulta indiferente para el derecho, es decir, no es igualmente justo que se aprecie o no la peligrosidad, la penosidad, etc.-, sino que se trata de actuación reglada, bien que con un, en este caso, amplio margen de apreciación para la Administración. Sobre esta base, en relación con el complemento específico hay que distinguir dos momentos: A) Actuaciones que preceden y tienden a la determinación del complemento específico. Aquí, ciertamente, la Administración ha de atender exclusivamente al contenido del puesto de trabajo en cuestión para aplicarle los criterios de valoración que se hayan adoptado. B) Fijado ya el complemento específico cabe una tarea de comprobación, que puede realizar la propia Administración, o de control, que desarrollan los Tribunales (artículo 106.1 de la Constitución), para examinar si la fijación del complemento específico ha sido o no legalmente procedente. $\mathrm{Y}$ en su curso resulta perfectamente viable comparar el «contenido» de varios puestos de trabajo -no el Cuerpo o Escala al que pertenecen los funcionarios que los desempeñan- para ver si el complemento específico fijado a los mismos resulta o no coherente con aquel «contenido»".

Ahora bien, una cosa es la ausencia de motivación y otra que la fundamentación de la fijación de los complementos específicos sea errónea. En este último caso, la jurisprudencia reconoce que, de la presunción de legalidad de los actos administrativos, hay que derivar también la presunción de que se ha respetado el principio de objetividad de la acción administrativa: "Pero para ello, ya en sede jurisdiccional, será precisa una prueba pericial con fuerza suficiente de convicción que llegue a destruir la objetividad que, en principio, hay que presumir en la decisión administrativa, máxime si viene avalada por una previa actuación especializada en el análisis y catalogación de puestos de trabajo, dado que se trata de materia en la que son «necesarios conocimientos científicos... o prácticos» (artículo 610 de la Ley de Enjuiciamiento Civil)“ (STS de 22 de diciembre de 1994).

Así, la STSJ de Castilla-La Mancha de 7 de febrero de 2007 considera la falta de objetividad y de criterios de valoración a la hora de fijar el complemento específico en la relación de puestos de trabajo del Ayuntamiento en cuestión. Se apoya dicha aseveración en un informe de fecha 22-4-2003 de la propia Secretaría del Ayuntamiento, que se acompaña con la demanda, donde se resalta que a pesar de los estudios encargados para realizar una valoración de puestos de trabajo no se ha implantado ninguno de ellos. De ello también se dejaba constancia en el informe de 2-3-87, que obra en 
el expediente administrativo donde se afirmaba: “En cuanto a la determinación de complementos específicos no se ha tenido en cuenta ni se ha efectuado una previa valoración de puestos de trabajo, tal como se detalla en el art. 4 del RD 861/86, de 25 de abril".

\section{PROVISIÓN DE PUESTOS DE TRABAJO Y PRINCIPIO DE OBJETIVIDAD: ¿ES COMPATIBLE LA LIBRE DESIGNACIÓN CON EL PRINCIPIO DE OBJETIVIDAD?}

El artículo 80 del EBEP establece la normativa básica sobre esta técnica de provisión, a la que empieza por denominar "libre designación con convocatoria pública”, inciso último recuperado de la originaria Ley 30/1984. Según la definición que hace este precepto, “consiste en la apreciación discrecional por el órgano competente de la idoneidad de los candidatos en relación con los requisitos exigidos para el desempeño del puesto". Serán las Leyes de Función Pública que se dicten en desarrollo del Estatuto las que establezcan los criterios para determinar los puestos que por su especial responsabilidad y confianza puedan cubrirse por el procedimiento de libre designación con convocatoria pública, por lo que la apreciación discrecional de la Administración a la hora de concretar, en las relaciones de puestos de trabajo, los que puedan ser provistos por esta técnica debe necesariamente ejercerse en el marco de los criterios legales -no reglamentarios de esa misma Administración- previamente establecidos.

La contradicción de esta técnica de provisión, basada en última instancia en la confianza que deposita el órgano que nombra sobre el funcionario, explican la continua conflictividad de esta técnica, no sólo a la hora de identificar los puestos que pueden ser provistos por esta técnica o en el momento de motivar los nombramientos, sino también desde el punto de vista de su constitucionalidad, por la posible vulneración de los principios de igualdad y de mérito y capacidad, por un lado, y del principio de objetividad, por otro.

Centrándonos en esta última perspectiva, la STC 235/2000, de 5 de octubre, afrontó directamente la constitucionalidad de está técnica, precisamente en una de sus aplicaciones más extremas: la relativa a los funcionarios con habilitación de carácter entonces nacional, que asumen funciones esenciales en la Administración local como las de control de legalidad y de tesorería, lo que determina su peculiar régimen jurídico de provisión para garantizar su independencia, imparcialidad y objetividad en el ejercicio de las citadas funciones. Pues bien, el Tribunal Constitucional comienza por "... sostener la constitucionalidad del sistema de libre designación, cuya entrada en juego no comporta que los principios de mérito y capacidad queden exclusivamente constreñidos al ámbito del concurso, en la medida en que (y con independencia... de que cuando se trata de la provisión de puestos de trabajo entre quienes ya ostentan la condición de funcionarios operen otros bienes y valores distintos de los que aquellos principios incorporan) la facultad de libre designación no atribuye al órgano 168 de decisión una especie de poder omnímodo a fin de decidir como tenga por conve- 
niente, con olvido de que el servicio del interés público es la esencia y el fundamento del ejercicio de toda potestad administrativa, con la consecuencia, en todo caso, de la eventual apreciación, con ocasión del oportuno control judicial "ex" artículo 106.1 de la Constitución, del vicio de desviación de poder de constatarse una marginación indebida de los principios de mérito y capacidad".

En lo relativo a los puestos que excepcionalmente se cubrirían mediante esta técnica, el Tribunal Constitucional señala que "los criterios utilizados para determinar los supuestos en los cuales puede acudirse al sistema de libre designación no son en modo alguno arbitrarios y carentes de un fundamento objetivo y razonable, pues viene a expresar que, sin perjuicio de la entrada en juego de los principios de mérito y capacidad (ya acreditados, por lo demás, en virtud de la previa habilitación de carácter nacional), la libre designación, que, en definitiva, y según se dirá más abajo, no significa sino la mera puesta a disposición del órgano decisor de un cierto margen de valoración a la hora de apreciar las aptitudes de los candidatos para desempeñar un determinado puesto de trabajo, queda reservada a los puestos que ofrecen una particular relevancia en el conjunto de la llamada Administración Local, sea por el tipo de entidad de que se trate, por la población de que disponga el municipio, por el presupuesto ordinario de la Corporación (requisito específico para el caso de los puestos de intervención o tesorería, que se exige con independencia de los anteriores: párrafo segundo del art. 99.2 LBRL) o, en definitiva, por el nivel de complemento de destino (el treinta), expresión en última instancia de la valoración objetiva del puesto de trabajo [art. 15.1 b) de la Ley 30/1984]. En esta tesitura, por tanto, el carácter directivo o la especial responsabilidad a que se refiere el art. 99.1, párrafo primero, de la Ley 7/1985 no es, en última instancia, sino expresión de la específica o más intensa incidencia en los correspondientes puestos de trabajo reservados a funcionarios con habilitación de carácter nacional de las características de algunas Corporaciones Locales, sea por su índole, población o presupuesto".

Mayor enjundia presenta el análisis de la libre designación desde la doble perspectiva constitucional de los principios de igualdad, mérito y capacidad, por un lado, y de los principios de objetividad e imparcialidad. Aunque la cita es larga, merece la pena su reproducción para apreciar convenientemente la derrota argumental por la que transcurre el Tribunal Constitucional:

Objetividad e imparcialidad son, para los recurrentes, los otros dos valores o principios puestos en cuestión por el sistema de libre designación aquí impugnado. En síntesis, viene a decirse, no puede reputarse que la posibilidad de la libre destitución de quien ha sido designado por el sistema de libre designación permita un ejercicio objetivo e imparcial ex art. 103.1 y 3 CE de las funciones que le corresponde desarrollar (fe pública y asesoramiento legal preceptivo; control y fiscalización interna de la gestión económico-financiera y presupuestaria; contabilidad, tesorería y recaudación). Frente a este argumento el Abogado del Estado, sin perjuicio de reconocer que el sistema de libre designación, por su propia esencia, puede matizar o debilitar la integridad de la imparcialidad a que se refiere el art. 103.3 CE (no así, se dice, la objetividad proclamada en el art. 103.1 CE, pues el mandato contenido en 
este precepto se dirige a la Administración Pública en cuanto tal, no a los funcionarios o servidores que la integran), entiende que dicho debilitamiento ha de ser ponderado a la vista de otros elementos (vinculación, en virtud del principio democrático -arts. 1.1 y $97 \mathrm{CE}-$, del alto funcionariado local con los representantes locales democráticamente elegidos; necesidad de evitar, en expresión del defensor de la Ley recurrida, el «mandarinato», siempre pernicioso, de dicho funcionariado) cuya concurrencia, en una labor de equilibrio de los intereses en presencia, justifica plenamente la solución adoptada.

Ciertamente este Tribunal ha admitido que, aun cuando los principios de igualdad, mérito y capacidad (arts. 23.2 y 103.3 CE) rigen, no sólo en el momento inicial del acceso a la función pública, sino también en los ulteriores de desenvolvimiento de la carrera administrativa o profesional de los funcionarios (por todas, STC 96/1997, de 19 de mayo, FJ 2), de tratarse de este segundo momento, el atinente a la provisión de puestos de trabajo, es legítima la toma en consideración, a la hora de decidir sobre aquella provisión, de otros valores o fines constitucionalmente lícitos. Así se ha dicho, con relación a los principios de protección de la familia (art. 39.1 CE) y de eficacia de la Administración (art. 103.1 CE), a propósito del llamado turno de consorte en los concursos de traslado de los funcionarios (SSTC 192/1991, de 14 de octubre, FJ 4, 200/1991, de 28 de octubre, FFJJ 3 y 4, con cita, en ambos casos, el ATC 1325/1988, de 19 de diciembre), o, a fin de hacer efectivo el principio de autonomía de los entes territoriales, como modulación del derecho de igualdad en los casos de movilidad interadministrativa ex art. 17 de la Ley 30/1984 (STC 156/1998, de 13 de julio, FFJ 3 y 4). Desde esta perspectiva, por tanto, y en línea con la argumentación del Abogado del Estado, habría de razonarse acerca de si la modulación o debilitamiento del principio de imparcialidad que comporta el sistema de libre designación, y su eventual consecuencia, la libre destitución, son o no admisibles ex art. 103.3 CE.

Pues bien, desde una perspectiva general, tanto el concurso como la libre designación (si bien esta última venga ex art. 99.2 LBRL con carácter excepcional; excepcionalidad que anteriormente quedó justificada al razonarse acerca de los principios de mérito y capacidad) son sistemas o modos de provisión de puestos de trabajo entre quienes ya ostentan la condición de funcionarios (con habilitación de carácter nacional en el caso que nos ocupa). Quiere decirse, por tanto, que la finalidad a que ambos sirven es la misma: la atribución, de acuerdo con la lógica de cada procedimiento, de determinados puestos de trabajo a aquellos funcionarios en quienes concurran, desde la óptica de los principios de mérito y capacidad, la cualificación e idoneidad precisas para el mejor y más correcto desempeño de las funciones anudadas a cada puesto. Que la adjudicación sea en el caso del concurso la consecuencia de la baremación, más o menos automática, de los méritos aportados, según lo dispuesto en la oportuna convocatoria, en tanto que en el sistema de libre designación se produzca como resultado de la apreciación (dotada, como es obvio, de una evidente connotación de discrecionalidad o, si se prefiere, de un cierto margen de libertad) que el órgano decisor se haya forjado a la vista del historial profesional de los candidatos o aspirantes, es indiferente desde la perspectiva del genérico estatuto funcionarial de la persona que finalmente resulte adjudicataria del puesto en cuestión. No nos hallamos aquí en presencia de nombramientos para cargos políticos, caracterizados por la libérrima decisión de quien sea competente 
para efectuar el nombramiento; ni ante la designación de personal eventual, cualificado, según el art. 20.2, párrafo segundo, de la Ley 30/1984, por la «confianza o asesoramiento especial» de las funciones que pueden encomendársele.

La confianza que, en este sentido, puede predicarse de la libre designación, en cuanto modo de provisión entre funcionarios de puestos de trabajo, es la que se deriva de la aptitud profesional del candidato, puesta de manifiesto en los méritos esgrimidos, esto es, en su historial funcionarial. Ahora bien, cuando se establece la libre designación como forma de provisión de un puesto de trabajo se alude a un régimen jurídico que, no solo presenta singularidades en la forma de nombrar a un funcionario para el puesto concreto, sino que también las ofrece en relación con la forma en que dicho funcionario puede ser cesado, y, lo que es más importante, con las consecuencias que dicho cese tiene para el funcionario afectado. Desde esta perspectiva nuestro control de constitucionalidad no se dirige ahora hacia el sistema de libre designación establecido en la legislación general de función pública, sino sólo y exclusivamente al diseñado en los preceptos impugnados, que afecta a un concreto grupo de funcionarios (los habilitados nacionales) y que encierra un régimen jurídico no totalmente coincidente con el que podríamos llamar general, para evaluar si queda comprometida la imparcialidad en el ejercicio de la función pública que debe garantizar la ley ex art. 103.3 CE.

Para afrontar esta cuestión conviene precisar, en primer lugar, que la imparcialidad en el ejercicio de la función pública viene garantizada ad extra, es decir, en las relaciones con los administrados, por una serie de cautelas legales, entre las que ocupa un lugar destacado la obligación de abstención y la posibilidad de recusación de los funcionarios cuando concurren determinadas circunstancias previstas legalmente que pueden poner en peligro objetivo la rectitud de su actuación (arts. 28 y 29 de la Ley 30/1992, de 26 de noviembre, de régimen jurídico de las Administraciones Públicas y del procedimiento administrativo común). Lo que está en cuestión es la vertiente interna de la imparcialidad, es decir, si la facultad de que el Presidente de la Corporación cese discrecionalmente en su puesto de trabajo al funcionario nombrado para él a través del sistema de libre designación coloca a dicho funcionario en una posición de debilidad tal que pueda comprometer la imparcialidad en el ejercicio de sus funciones.

Pues bien, partiendo de que el libre cese que acompaña a la libre designación no es incompatible en abstracto con el ejercicio imparcial de las funciones públicas, lo cierto es que en el supuesto que contemplamos la Ley impugnada configura el sistema con ciertas garantías suplementarias en atención a la importancia de las funciones atribuidas a estos funcionarios. En primer término, si bien su nombramiento es decidido por el Presidente de la Corporación de entre quienes ya cuentan con habilitación nacional y cumplen los requisitos de la convocatoria, ha de haberse modificado previamente la correspondiente relación de puestos de trabajo para fijar el sistema de libre designación como forma de provisión del puesto de trabajo (art. 99.2 párrafo 1 de la norma impugnada), lo cual corresponde al Pleno de la Corporación por aplicación de los arts. 22.2 i) y 33.2 f) de la Ley $7 / 1985$, de 2 de abril, reguladora de las Bases del Régimen Local, y del mismo modo es el Pleno de la Corporación el que aprueba las bases de la convocatoria. Esta intermediación del Pleno corporativo significa, en suma, una autorización al Presidente por parte del 
órgano supremo de la Corporación, sin la cual el sistema de libre designación no puede ser aplicado.

En lo referente al cese, este se puede acordar por el Presidente de la Corporación, y, si bien el art. 99.2 párrafo 2 impugnado no dice expresamente que tenga carácter discrecional, parece presuponerlo, como lo confirma el desarrollo reglamentario (art. 29 del Real Decreto 1732/1994, de 29 de julio, sobre provisión de puesto de trabajo reservados a funcionarios de Administración local con habilitación de carácter nacional). Ahora bien, también en este aspecto la regulación legal cuya constitucionalidad se cuestiona otorga alguna garantía suplementaria al funcionario cesado libremente. Así, el art. 20.1 e) de la Ley 30/84, de 2 de agosto, de medidas para la reforma de la función pública, nada prevé en cuanto al destino del funcionario cesado, sino que es el art. 58 del Real Decreto 364/1995, de 10 de marzo, por el que se aprueba el Reglamento general de ingreso del personal al servicio de la Administración General del Estado y de provisión de puestos de trabajo y promoción profesional de los funcionarios civiles de la Administración General del Estado, el que garantiza al funcionario cesado la adscripción provisional a un puesto de trabajo correspondiente a su cuerpo o escala, no inferior en más de dos niveles al de su grado personal en el mismo municipio, en tanto no obtenga otro con carácter definitivo. En cambio los preceptos impugnados, de rango legal, garantizan al funcionario cesado un puesto de trabajo de su subescala y categoría en la Corporación que tendrá asignadas funciones de «colaboración, apoyo y asistencia jurídica o económica», y que deberá figurar en la correspondiente relación de puestos de trabajo, lo que constituye una garantía suplementaria para el funcionario que mitiga razonablemente las consecuencias que la pérdida de confianza inherente al cese le pudieran acarrear, y por ende le colocan en una mejor posición para ejercer sus funciones con la imparcialidad requerida.

De todo lo anterior se sigue que, ni el sistema de libre designación para puestos de indudable relevancia por su carácter directivo y especial responsabilidad es en abstracto contrario al art. 103.3 CE, ni tampoco en el presente supuesto, aun partiendo de la importancia de las funciones de asesoramiento legal y económico, o de control financiero y presupuestario encomendadas a los funcionarios con habilitación nacional, queda comprometida la imparcialidad que la ley debe preservar para el ejercicio de las funciones públicas según el citado artículo. Tampoco hay, por supuesto, vulneración del principio de objetividad (art. 103.1 CE), que, aplicable a todas las Administraciones Públicas (STC 85/1983), tiene por destinatarias a éstas, justamente, en cuanto sujetos de Derecho.

Muchas han sido las críticas que esta sentencia ha merecido, pero -desde la perspectiva de nuestro estudio- bastaría con que nos fijáramos en la inconsistencia de la argumentación relativa a que no nos hallamos aquí en presencia de nombramientos para cargos políticos, caracterizados por la libérrima decisión de quien sea competente para efectuar el nombramiento; ni ante la designación de personal eventual, cualificado por la «confianza o asesoramiento especial» de las funciones que pueden encomendársele, sino que -según el Tribunal Constitucional- la confianza que, en este sentido, puede predicarse de la libre designación, en cuanto modo de

172 provisión entre funcionarios de puestos de trabajo, es la que se deriva de la aptitud 
profesional del candidato, puesta de manifiesto en los méritos esgrimidos, esto es, en su historial funcionarial". El sofisma del razonamiento radica en intentar trasladar el objeto de la confianza (los méritos del candidato) al sujeto de la misma (el órgano que nombra), en un intento de objetivizar la libre designación. Sin embargo, la confianza es una realidad subjetiva: o se tiene o no se tiene y para tenerla no bastan exclusivamente los méritos (o "aptitud profesional") del funcionario, pues es producto de muchos factores. Factores psicológicamente explicables pero jurídicamente ilegítimos en una Función Pública profesional basada en los principios de igualdad y de mérito y capacidad. La ceremonia de la confusión por la que discurre la argumentación que intenta matizar la virtualidad de estos principios en la carrera funcionarial en beneficio de otros bienes o valores (eficacia, autonomía local inclusive, etc.) no hace sino revelar la contradicción intrínseca de esta técnica con la Función Pública.

Solventada técnicamente la constitucionalidad del sistema de libre designación, el siguiente escenario de la complejidad tiene lugar a la hora de concretar los puestos de trabajo que podrán ser provisto mediante esta técnica. En la medida en que la Administración se sacude de los constreñimientos del concurso, donde el mérito y capacidad se han articulado mejor (aunque tampoco de manera óptima), aquella ha sido propensa a extender lo más posible los ámbitos de libre designación, no sólo por poder hacer valer otros criterios para nombrar a los funcionarios en esos puestos sino también porque los puede cesar en cualquier momento y por esos mismos criterios, que, por mucho que argumente la jurisprudencia, se suelen reconducir a la estricta confianza que uno tiene en el otro. La jurisprudencia se ha visto obligada a analizar caso por caso y, por tanto, puesto por puesto ${ }^{6}$, si las justificaciones que alegaba la Administración para determinar que la forma de provisión fuese la libre designación respondían a las singulares funciones (de especial responsabilidad y de dirección) que son propias de esta figura.

La STS 5 de junio de 2009 sintetiza acertadamente el marco de la cuestión: "bien puede afirmarse que el sistema de libre designación previsto en la Ley difiere sustancialmente de un sistema de libre arbitrio, ya que su perfil viene delimitado por los siguientes elementos: Primero: Tiene carácter excepcional, en la medida que completa el método normal de provisión que es el concurso. Segundo: Se aplica a puestos de-

6 Por ejemplo, la STSJ de Asturias de 16 de diciembre de 2011, que analiza más de un centenar de puestos de la Administración del Principado de Asturias. A título de ejemplo: “Consejería de Presidencia, Justicia e Igualdad. Secretaria General Técnica: Jefe de Servicio del Secretariado del Gobierno, nivel 30. Examinado el expediente se dice en la propuesta que el puesto de trabajo está bajo la dependencia jerárquica directa de la persona titular de la Secretaría General Técnica, que, a su vez, depende directamente del titular de la Consejería. Es decir que está a tercer nivel de responsabilidad, y enumera sus funciones. Pues bien, examinadas las funciones no se vislumbra motivo alguno de por qué esas funciones no las puede desarrollar el funcionario elegido por concurso, ya que da por supuesto el informe que dichas funciones conllevan la especial responsabilidad que se le atribuye, cuando resulta que son de gestión administrativa ordinaria, pues ni se comprende ni se explica cual es ese importante nivel de conocimientos jurídicos que se requiere para el desempeño de las funciones descritas en la propuesta, ni esa especial responsabilidad y dedicación. La justificación es estereotipada, de un lado, y de otro, la dependencia de otro cargo directivo relativiza su carácter directivo". 
terminados en atención a la naturaleza de sus funciones. Tercero: Sólo entran en tal grupo los puestos directivos y de confianza que la Ley relaciona (secretarías de altos cargos y los de especial responsabilidad). Cuarto: La objetivación de los puestos de esta última clase («especial responsabilidad») está incorporada a las relaciones de puestos de trabajo, que deberán incluir, «en todo caso, la denominación y características esenciales de los puestos», y serán públicas, con la consecuente facilitación del control".

\section{LAS NOVEDOSAS TÉCNICAS DE GESTIÓN DE RECURSOS HUMANOS EN LA FUNCIÓN PÚBLICA DESDE LA PERSPECTIVA DEL PRINCIPIO DE OBJETIVIDAD}

La nueva cara de la recurrente reforma y modernización de la Función Pública es la implantación de técnicas científicas de gestión de recursos humanos que legitimarían aquella sobre bases de eficacia y eficiencia. A estas técnicas se les atribuye un poder taumatúrgico para solucionar los problemas de selección de funcionarios, de definición material de puestos de trabajos y, por supuesto, de carrera administrativa. Asistimos, en efecto, a la imparable irrupción de novedosas técnicas de gestión que pretenden erigirse en la panacea de todos los males de la Función Pública tradicional. Si en la década de los ochenta la solución se identificaba con el definitivo reconocimiento del contrato laboral en las Administraciones Públicas, los albores del siglo XXI contemplan el asalto de soluciones organizativas o funcionales originadas en la psicología de las organizaciones, en la ciencia de la Administración, en la gestión de recursos humanos o directamente en la empresa privada. Su trasplante y adaptación a las Administraciones Públicas evidentemente es problemático, pero en modo alguno puede soslayar la legalidad a la que se deben aquellas. En efecto, la gestión pública no puede prescindir del Derecho ni la Administración (o sus "gestores") pueden camuflar normas jurídicas en un paniaguado "soft-law" de manuales de gestión o enmascarar actos administrativos en pretendidos inocuos actos de gestión, prescindiendo para ello de las garantías que supone el procedimiento administrativo previo o de las más básicas exigencias de motivación de los actos administrativos (disimulada no pocas veces en complejas e ininteligibles fórmulas matemáticas). Desde este punto de vista, el principio de objetividad debe informar tanto el diseño de estas técnicas como su aplicación concreta, pues el peligro de que estas técnicas de gestión enmascaren arbitrariedades, encauzando veladamente decisiones políticas o nepóticas, es muy grande

\section{Objetividad en la evaluación del desempeño}

Una de las más importantes novedades del Estatuto Básico del Empleado Público de 2007 es la obligación de implantar en cada Administración sistemas de evaluación del desempeño de todos los empleados públicos, señalando la Ley, entre otras

174 exigencias, que esos sistemas deberán respetar criterios de objetividad e imparciali- 
dad. Para apreciar la importancia de estos criterios en la configuración y en la aplicación de los procedimientos de evaluación del desempeño, podemos analizar alguna sentencia en el pionero ámbito de la Función Pública sanitaria, donde ya se preveían, con anterioridad al EBEP, estos sistemas.

En efecto, la Función Pública sanitaria es buena muestra de la relación entre el principio de objetividad y la implantación de sistemas de evaluación del desempeño, desde que la Ley 44/2003, de 21 de noviembre, de ordenación de las profesiones sanitarias, estableciera una carrera profesional estructurada en grados que se van adquiriendo después de evaluaciones llevadas a cabo por Comités específicos, donde se asegura la presencia de evaluadores externos. Estas evaluaciones tendrán por objeto los méritos del interesado, en relación a sus conocimientos, competencias, formación continuada acreditada, actividad docente e investigación, teniendo también en cuenta los resultados de la actividad asistencial del interesado, la calidad de la misma y el cumplimiento de los indicadores que para su valoración se hayan establecido, así como su implicación en la gestión clínica. Finalmente, la Ley establece un plazo de cinco años para pedir una nueva evaluación y, en el caso de ser negativa la evaluación obtenida, el profesional podrá pedir una nueva evaluación transcurridos tan sólo dos años. Siendo ésta la legislación básica, cada Comunidad Autónoma debe desarrollar la carrera administrativa en el seno de sus Servicios de Salud.

Un ejemplo de las complejidades de regulación y de las dificultades de gestión de este tipo de carreras horizontales lo observamos en la Sentencia del Tribunal Supremo de 12 de marzo de 2012 y la de instancia, del Tribunal Superior de Justicia de Andalucía, 22 de diciembre de 2009. El caso tenía por objeto el Acuerdo que la Junta de Andalucía había firmado con las organizaciones sindicales para regular la carrera administrativa en el Servicio de Salud de Andalucía, desarrollando las disposiciones básicas del Estado antes mencionados.

Comenzando con las apreciaciones de la Sentencia del Tribunal Superior de Justicia, de 22 de diciembre de 2009, ésta se enfrenta en primer lugar al objeto de las evaluaciones, por cuanto "La redacción del epígrafe 5.2.1 del Acuerdo recurrido [establece que el baremo de méritos para el personal licenciado y diplomado sanitario y licenciado y diplomado de gestión y servicios está compuesto por los factores: CRP (cumplimiento de los objetivos de la organización), EDP (desarrollo profesional), Formación, Compromiso con la Organización, Docencia e Investigación.] reseña todos los elementos valorables delimitados en la legislación estatal, pero añade el relativo al compromiso con la organización. En principio, podría considerarse que la Comunidad Autónoma, en el ejercicio de sus facultades de desarrollo de la legislación estatal y en ejercicio de las concretas competencias para las que le habilita el anteriormente referido art. 40.4 del Estatuto Marco, procede a establecer otro factor computable a los efectos de baremar la carrera profesional; pero la Sala entiende que "el compromiso con la organización", factor de constatación netamente subjetiva, debe entenderse ya medible a través del CRP (cumplimiento de los objetivos de la organización), sin que sea factible duplicar los factores atendibles en la baremación de los méritos.". 
El Tribunal identificó aquí un primer elemento ilegal no solo por duplicar los criterios de valoración sino también por incluir criterios subjetivos, contrarios por tanto al principio de objetividad que informa el Derecho de la Función Pública.

A continuación, la sentencia analiza la concreta articulación, periodicidad y efectos de las evaluaciones, en particular el mantenimiento y descenso de los niveles ya obtenidos en la carrera. El Acuerdo establecía que "una vez certificado dos veces consecutivas el mismo nivel de carrera será posible el mantenimiento por un periodo indefinido, sin necesidad de volver a recertificar el mismo"; y su apartado cuarto, establece que "el no superar el proceso de certificación será la condición que determine que un profesional descienda a un nivel inferior de carrera”. En cuanto al proceso de certificación, se desglosan las tres situaciones que derivarían como resultado global de tal proceso, y concretamente: la promoción, el mantenimiento o el descenso. Y concretamente respecto del descenso, el Acuerdo impugnado precisaba: "el profesional, o bien no obtiene el número de puntos establecido como mínimo para el mantenimiento en un determinado nivel se produciría el descenso del nivel actual a un nivel inferior (aun cuando se mantenga el nivel de acreditación de competencias profesionales requerido para ese nivel o para el nivel superior)". Y en lo relativo a la periodicidad en la certificación de la carrera profesional, se exige o una petición de promoción a nivel superior o una petición de recertificación para mantenerse en el mismo nivel, una vez transcurridos cinco años desde la última evaluación. Y se establece, para el caso de haber transcurrido estos cinco años desde la última evaluación sin haber efectuado las solicitudes referidas, que la solicitud se realizará de oficio, teniendo que presentar el profesional, en el plazo máximo de seis meses, los documentos que acrediten el mantenimiento en ese nivel de carrera, y de no presentar la documentación, se entenderá que el profesional no cumple los requisitos para el mantenimiento y se producirá el descenso de nivel.

Pues bien, la argumentación del Tribunal no tiene desperdicio: “Ha de atenderse a que la carrera profesional se ha de entender como un proceso en el cual el profesional sanitario puede progresar en una escala de niveles que se correlacionan con su competencia para el ejercicio de la profesión, sus conocimientos, formación, actividad docente e investigación; progresión, que en términos semejantes a la carrera funcionarial, implica la posibilidad de promoción, sin que pueda encarnarse un sistema en el que se prevea el regreso. La exclusión de este regreso o descenso a niveles inferiores deriva incluso de la propia normativa básica, y en concreto del apartado c) del art. 38 de la Ley 44/03, que establece los periodos mínimos para que proceda la evaluación para acceder a los grados superiores y reseña expresamente que "en caso de evaluación negativa, el profesional podrá solicitar una nueva evaluación transcurridos dos años desde ésta". Lo cual significa, que, la nueva evaluación de la competencia y de los méritos ha de efectuarse para posibilitar el acceso a niveles superiores, pero no para ratificar o "recertificar" lo ya certificado anteriormente (en relación con el sistema de mantenimiento del nivel regulado por el Acuerdo andaluz impugnado) ni para provocar el regreso a niveles inferiores (en relación con el sistema de descen176 so regulado por el Acuerdo andaluz recurrido); determinando que, en caso de resul- 
tar una evaluación negativa, el nivel adquirido ha de mantenerse, imponiendo al profesional un plazo (de dos años) durante el cual no podrá solicitar una nueva evaluación (tendente al ascenso, claro está).

»Además, ha de determinarse lo perverso de la normativa regulada por la Comunidad Autónoma Andaluza, (aún con la previa negociación colectiva), relativa a que el descenso puede producirse, como resultado de la evaluación o reevaluación sobre los mismos méritos, aún en el caso de que se mantenga el mismo nivel de acreditación de competencias profesionales (como precisa, entre paréntesis, el último apartado del epígrafe quinto, relativo a la situación de descenso como resultado global); lo cual supondría que, acreditados los mismos conocimientos, cualidades, habilidades y aptitudes (por otro lado, incluir dentro de las competencias las "actitudes" y "motivaciones" para predisponer a realizar un conjunto de actividades con un buen nivel de desempeño, como establece el penúltimo apartado de la Exposición de Motivos del Anexo V del Acuerdo recurrido, ha de considerarse excesivo, en cuanto que incide en aspectos tan subjetivos e interiorizados por cada profesional, que no pueden ser objeto de baremación objetiva) y subsistiendo, respecto del baremo de méritos, los mismos factores anteriormente valorados, relativos a formación, docencia e investigación (los cuales existían y siguen existiendo como méritos por haberse acreditado en un momento anterior); pueda darse una baremación menor, con el siguiente descenso de nivel de carrera profesional, tan sólo por el concepto de "compromiso con la organización" u "obtención de los resultados fijados por la organización”, que, además de ser unos conceptos netamente subjetivos, no dependen sólo de los profesionales sanitarios, sino esencialmente de los medios personales y materiales facilitados por la propia Administración Pública, y que, además, resultarían considerados para atender a otros conceptos retributivos como pueden ser la exclusividad de la prestación sanitaria en las instituciones públicas o el complemento de productividad. Además, este sistema de regresión más parece el resultado de un proceso sancionador, establecido sin las propias garantías exigidas a éste, que las propias de un modelo de carrera profesional. Por todo lo anterior, la Sala llega a la conclusión de que la normativa recurrida referente al sistema de recertificación a efecto de mantenimiento en un nivel ya previamente acreditado y al sistema de descenso a niveles inferiores debe ser anulado en cuanto atenta contra la normativa básica estatal y afecta a la esencia de lo que debe entenderse como carrera profesional".

Además de la contradicción con la legislación básica, merece la pena destacar el último inciso de que lo establecido en el Acuerdo "afecta a la esencia de lo que debe entenderse como carrera profesional”. Dos cuestiones, en el contexto de las técnicas de gestión y del procedimiento de evaluación del desempeño, es necesario resaltar. En primer lugar, la incorporación de criterios técnicos de naturaleza subjetiva cuya valoración resulta imposible de aplicar objetivamente y, por tanto, de controlar a posteriori. En segundo lugar, la tenue separación entre evaluación negativa y potestad disciplinaria, con lo que se plantean problemas no sólo de desviación de poder sino de garantías mínimas de los derechos de los funcionarios, tal y como destacó en casación el Tribunal Supremo. 
En efecto, la Sentencia del Tribunal Supremo de 12 de marzo de 2012 señaló que "No nos parecen discutibles las consideraciones que hace la Junta de Andalucía sobre el significado que la Ley 44/2003 da a la formación permanente, ni cabe desconocer la importancia que para la asistencia sanitaria tiene el conocimiento y dominio de los avances científicos y tecnológicos. No nos parece que pueda concebirse ningún modelo de carrera profesional que los desconozca. De igual modo, no vemos incompatible con los principios sentados al respecto por las leyes estatales que los correlativos derecho y obligación de los profesionales sanitarios a la formación permanente proclamados por el artículo 33.1 de la Ley 44/2003 vayan acompañados de sistemas de comprobación de la misma. Ahora bien, cosa distinta es que mediante un acuerdo como el que nos ocupa se establezcan requisitos o efectos, no sólo no previstos por la Ley, sino que van más allá de las prescripciones legales. El artículo 38 de la Ley 44/2003 relaciona el desarrollo de la carrera de los profesionales sanitarios con la superación de diversas evaluaciones de sus conocimientos, competencias, formación continuada acreditada, actividad docente e investigación y, también, de los resultados de su actividad asistencial, de la calidad de la misma y del cumplimiento de los indicadores que para su valoración se hayan establecido e, incluso, de su implicación en la gestión clínica. Ese desarrollo lo concibe esta Ley en forma de adquisición del grado inicial y de sucesivos ascensos, evaluación favorable mediante, hasta el cuarto y último, debiendo transcurrir un mínimo de cinco años desde la anterior positiva para solicitar la correspondiente al siguiente. Ahora bien, su artículo 38.1 c), que contempla expresamente el supuesto de que la evaluación sea negativa, no le atribuye más consecuencia que la imposibilidad de ascender y el reconocimiento al interesado del derecho a solicitar una nueva transcurridos dos años, durante los cuales no podrá ascender. No hay fundamento legal, por tanto, para asignar a las evaluaciones negativas el efecto de producir el descenso de grado o, si se prefiere, de impedir la conservación del ya adquirido. $Y$ en la medida en que la ley no contempla esa posibilidad, tampoco admite la de someter el mantenimiento del que ya se tiene a comprobaciones o evaluaciones periódicas. Tales requisitos, por ser restrictivos de derechos, han de estar previstos en la Ley. Y las aplicables, no sólo no los incluyen sino que, además, orientan el sistema de evaluaciones solamente hacia el ascenso".

La Sentencia destaca, por tanto, otro de los problemas que plantean las nuevas técnicas de gestión de recursos humanos: su necesaria cobertura legal. En el asunto en cuestión, se trataba de su manifestación más intensa, esto es, la necesaria reserva de ley que exige toda limitación de derechos. Pero más peligrosas son todas esas previsiones que ni siquiera están contenidas en norma alguna y que únicamente se recogen en manuales, guías, prontuarios o cualquier clase de documento carente de la más mínima eficacia jurídica, pero que son aplicados religiosamente por los técnicos en recursos humanos.

\section{Objetividad y entrevistas y pruebas psicotécnicas}

Una de las técnicas más usadas en este contexto de valoración de los méritos y de 178 las aptitudes de los funcionarios a efectos de selección o de provisión es la realización 
de entrevistas y pruebas psicotécnicas. De hecho, el art. 61.5 del Estatuto Básico del Empleado Público autoriza recurrir a ellas "para asegurar la objetividad y la racionalidad de los procesos selectivos". No obstante, que sean técnicamente posibles no implica que sean legalmente viables, lo que explica la conflictividad que han suscitado.

En lo que respecta al carácter de la entrevista en sí misma y su análisis desde el punto de vista jurídico, es imprescindible estudiar la Sentencia del Tribunal Supremo de 8 de marzo de 2011, donde se analiza la legalidad de la técnica de la «entrevista conductual estructurada» ${ }^{7}$. La Sentencia de 14 de mayo de 2008 de la Sala de lo Contencioso-Administrativo del Tribunal Superior de Justicia del País Vasco había anulado la Orden del Departamento de Hacienda y Administración Pública del Gobierno Vasco, por la que se regula el procedimiento para la provisión en comisión de servicios de puestos de trabajo de la Administración General de la Comunidad Autónoma y de sus Organismos Autónomos "por la ausencia de una cumplida justificación que autorice a concluir que su utilización está plenamente respaldada por el método científico, justificación que no aparece en el expediente administrativo ni se ha ofrecido en fase probatoria mediante una cumplida prueba pericial. Únicamente se ha aportado una fotocopia de un documento cuya lectura no autoriza a extraer nada concluyente. $\mathrm{Ni}$ permite determinar el campo del saber en que cabe incardinar la utilización de la llamada entrevista conductual estructurada, ni realmente en qué consiste y cuáles son sus fundamentos y anclajes en la doctrina científica. Su acusada subjetividad la hace incompatible con el principio constitucional de acceso en condiciones de igualdad a la función pública de acuerdo con los principios de mérito y capacidad, y con los requisitos que señalen las leyes, en la medida en que dicha metodología no ha sido recepcionada en la legislación funcionarial por Ley alguna, y de otro lado no queda justificada debidamente que se cohoneste con los principios de mérito y capacidad, únicos cánones válidos para seleccionar al personal de la Administración pública, que a diferencia de los agentes privados que en el momento de la selección de su personal obran con la más amplia libertad, se halla constreñida por una estricta legalidad procedimental en garantía precisamente del principio de igualdad en el acceso de todos los aspirantes".

7 Según la Orden en cuestión, la entrevista conductual estructurada (ECE) es uno de los medios para valorar el mérito y la capacidad de los aspirantes a desempeñar en comisión de servicios unos determinados puestos de trabajo: Ios de los grupos A o A/B con nivel de encuadramiento I y II. Esa entrevista ha de anunciarse en la resolución de convocatoria con indicación del día y hora de su celebración y en ella se valorarán, conforme a un baremo preestablecido, las competencias necesarias para el buen desempeño del puesto. Los entrevistadores actúan en los órganos de valoración bajo la dependencia funcional y como representantes de la Viceconsejería de Función Pública y han de ser designados a partir de una lista formada por quienes hayan superado un curso de homologación en ECE organizado u homologado por el Instituto Vasco de Administración Pública. Sus funciones son: “a) Recabar información de los expertos, mediante la metodología acordada por la Dirección de Función Pública, acerca de los conocimientos y destrezas adecuados para un buen desempeño del puesto. b) Determinar las dimensiones relevantes del puesto. c) Diseñar la entrevista y los criterios de evaluación. d) Exponer y formar a los demás miembros de la comisión en los criterios para evaluar las entrevistas. e) Realizar y evaluar las entrevistas. f) Obtener los indicadores de fiabilidad y validez establecidos. g) Enviar a la Dirección de Función Pública la grabación de las entrevistas e introducir en la base de datos preparada al efecto los datos recogidos y elaborados para el diseño y evaluación de la entrevista: incidentes críticos, dimensiones, preguntas, anclajes”. 
El Gobierno vasco, en casación argumentó contra la sentencia por decir que la ECE no está mínimamente respaldada por el método científico cuando con la contestación a la demanda se aportó un artículo científico publicado en la Revista de Psicología del Trabajo y de las Organizaciones entre cuyos autores figura un catedrático de Psicología Social de la Universidad de Santiago de Compostela y el documento que recoge el diseño de la ECE para el puesto de letrado asesor de la Dirección de Política Autonómica y Desarrollo Estatutario. Subrayó, además, que la entrevista es el método de selección de personal más utilizado por los profesionales de recursos humanos, que está previsto por la vigente Ley $6 / 1989$, de 6 de julio, de la Función Pública Vasca, además de por el Estatuto Básico del Empleado Público. Por otra parte, el Gobierno vasco aclaró que no todas las entrevistas son iguales, diferenciando las estructuradas de las convencionales, que son las que carecen de un formato estandarizado mientras que en la ECE los candidatos se someten todos a las mismas preguntas y por el mismo orden, preguntas que han de ser preparadas antes de la entrevista y ser fruto de un riguroso análisis del puesto a proveer. En este sentido, dice que se optó por la ECE por pretender que las preguntas se refirieran únicamente a los desempeños laborales previos de todos los aspirantes, se hicieran a todos por el mismo orden y versaran sobre sus comportamientos laborales previos y relevantes para el puesto. Expuso también las características técnicas de la ECE e informó que se venía utilizando en la Administración vasca desde varios años antes. Y destaca su fiabilidad, objetividad -es grabada, entre otras razones, a efectos de su control posterior, de ser preciso-y validez predictiva, considerándola imprescindible. Además, recuerda que en el interrogatorio de parte, practicado a instancias de la demandante, no se cuestionó el carácter científico de la ECE. Sólo se planteó la duda de si valora la personalidad del candidato o el desempeño voluntario de cometidos o asignaciones extra, duda, prosigue, que fue despejada pues la ECE no mide la personalidad sino las destrezas o desempeños laborales en relación con el puesto de trabajo. $Y$, subraya que teniendo la Sala cauces para cuestionar la ECE no los utilizó, pero sin prueba alguna que la desvirtúe endosa a la Administración la carga de probar su carácter científico. Tal apreciación la tiene el motivo por desproporcionada y contraria al artículo 217 de la Ley de Enjuiciamiento Civil y causante de indefensión para ella. En suma, sostiene el recurrente que la sentencia, ha "prescindido absolutamente de motivar y razonar por qué la Orden de 30 de mayo de 2006, incurre en arbitrariedad a la hora de garantizar la cualificación profesional de los entrevistadores que forman parte de la comisión de valoración (art. 22 de la citada Orden)".

El Tribunal Supremo cede ante esta argumentación con una motivación bastante pobre: partiendo de la presunción de validez de la actuación de la Administración, considera que ni el recurrente ni la Sala desvirtuaron tal presunción, pero no analiza si la técnica aplicada es respetuosa con los principios básicos constitucionales de la Función Pública, en particular la igualdad y la objetividad de la acción administrativa: “Este reconocimiento legal y reglamentario de la entrevista como método idóneo para seleccionar a los empleados públicos conforme a los principios de mérito y capacidad y con respeto al de igualdad, se extiende a todas sus posibles formas salvo a 180 aquellas que se demuestren incompatibles con las premisas constitucionales sobre 
las que descansa la función pública. Por tanto, la cuestión se desplaza, no al rango de la disposición que la incluye en el procedimiento de provisión, mediante comisión de servicios, no de todos, sino de determinados puestos -los de responsabilidad, según explica el preámbulo de la Orden- y entre quienes son ya funcionarios sino a su conformidad con tales postulados del texto fundamental. Conformidad que, en principio, ha de suponérsele ya que no hay razón para excluirla de la presunción de validez que corresponde a los actos y disposiciones de la Administración según el artículo 57.1 de la Ley 30/1992. Así, pues, corre de cuenta del recurrente desvirtuarla y en este caso no lo ha hecho y, desde luego, la sentencia no explica por qué descalifica la ECE ya que, más allá de las rotundas manifestaciones que le dedica no señala en virtud de qué concretos motivos llega a ellas ni por qué no da valor a un artículo científico publicado en una revista de esa misma naturaleza y obra de autores a los que ha de reconocérseles la capacidad técnica para opinar al respecto".

En lo tocante a las pruebas psicológicas, la jurisprudencia ha sido más escéptica en su aplicación concreta, aunque no la desautorice con carácter general. Buena muestra de ello es la STS de 27 de febrero de 2012. Con carácter general, señala que “el artículo 21 del Reglamento de Régimen Interior de la Academia de Policía del País Vasco, aprobado por Orden del Departamento de Interior de 22 de febrero de 1982 y modificado por la de 12 de febrero de 1990, impone el sometimiento de los alumnos a una Valoración de Actitudes a realizarse en la forma determinada por la Dirección de la Academia de acuerdo con los principios de discreción y objetividad y con efectos eliminatorios, caso de no superarse. Por otro lado, además de recordar con la sentencia antes invocada que la evaluación de la personalidad es un aspecto sumamente valioso de los procesos de selección de los futuros integrantes de la policía, debemos decir que, con los elementos obrantes en el proceso, no nos consideramos en condiciones de descalificar en términos generales el sistema establecido en la Academia de Policía del País Vasco para llevar a cabo dicha evaluación a falta de dictámenes de carácter pericial desde el punto de vista de su adecuación a los principios constitucionales de mérito y capacidad".

No obstante, en el caso de pruebas que evalúan la capacidad del interesado de entablar relaciones sociales o interpersonales, éstas se pueden ver invalidadas por las propias circunstancias fácticas. En el caso en cuestión, se trataba de un aspirante que había sido objeto de vejaciones y de novatadas por parte del resto de candidatos, de ahí que se constatara "la existencia de un tipo de relaciones entre los alumnos del grupo de la promoción absolutamente inadmisible y, desde luego, inidóneo para que pueda darse validez alguna a pruebas que descansan en la opinión de esos alumnos. Es decir, la existencia de grupos que bajo la incitación de quienes se erigen en sus impulsores crean un clima de animadversión o desprecio contra algunos compañeros sin que haya razón que lo justifique invalidan tales pruebas desde el punto de vista de la objetividad como medio de medir o evaluar las actitudes relevantes para la función policial pues las respuestas dadas por la mayoría obedecen, no a percepciones espontáneas relacionadas con cometidos profesionales, sino a la imagen distorsionada" que habían difundido los autores de las citadas vejaciones. La impresión negativa del 
aspirante que se había extendido entre todos los demás aspirantes a policía invalidaba la prueba del «sociograma».

También merece la pena traer a colación la anterior STS de 26 de marzo de 2007, donde la argumentación formal discurrió por la ausencia de previsión normativa sobre este tipo de pruebas, no considerándose suficiente ni la formulación de las bases del proceso selectivo ni la aplicación que de las mismas hizo el Tribunal de oposiciones: "la correcta interpretación de la Base Séptima no permite el establecimiento de un sistema de evaluación de la conducta paralelo y distinto al estrictamente académico. Es cierto que el mero dato del conocimiento no es suficiente para tener por superado el curso. Es el mínimo necesario. Ahora bien, cuando se habla de aptitud en el contexto de un curso selectivo de Mossos d'Esquadra, se está pensando en la aptitud profesional. A ella han de referirse el mérito y la capacidad. Y cuando se prevé la evaluación continuada del aprovechamiento global, si no se dice otra cosa, se está considerando el relacionado directamente con los contenidos formativos del curso. Es decir, con los consignados en el plan de estudios. Ese es el aprovechamiento contemplado por la Base Séptima y sobre él debe formularse el juicio de aptitud. Es significativo, en este sentido, que la Escuela, en la calificación que denomina «académica», no se haya limitado a puntuar solamente el conocimiento de una materia sino, también, la actitud observada por el alumno, es decir, su actitud ante las enseñanzas que ha cursado. En otras palabras, su aprovechamiento. La apreciación de la morfología conductual de los aspirantes y la utilización de su valoración como elemento autónomo y determinante de su exclusión a través de todo un complejo conjunto de técnicas y procedimientos es un añadido que excede claramente de los términos de la convocatoria". En cuanto a la perspectiva material, el Tribunal Supremo señaló que "tienen razón la Generalidad de Cataluña y la Sentencia cuando resaltan la relevancia de la evaluación de la conducta y de los factores relacionados con la personalidad a la hora de seleccionar a los futuros Mossos 'Esquadra pues, ciertamente, esos elementos son sumamente valiosos desde el momento en que ofrecen datos muy importantes para identificar a los aspirantes más adecuados para desempeñar la función policial", por lo que la ilegalidad derivada de la ausencia de cobertura normativa de las pruebas psicológicas de evaluación de la conducta "no tiene nada que ver con lo razonable y útil que pueda ser ese tipo de análisis para escoger a los mejores de entre los alumnos de la Escuela".

Por tanto, las pruebas psicológicos deben pasar por el tamiz de su legalidad formal y material, lo cual en ocasiones puede ser complejo por la técnica con que aquellas se diseñan y que, obviamente, escapa al saber jurídico. 